\title{
Short Communication: Identification of Diseased Calves by Use of Data from Automatic Milk Feeders
}

\author{
C. Svensson*1 and M. B. Jensen† \\ *Department of Animal Environment and Health, Swedish University of Agricultural Sciences, P.O. Box 234, SE-532 23 Skara, Sweden \\ †Department of Animal Health, Welfare and Nutrition, Danish Institute of Agricultural Sciences, Research Centre Foulum, P.O. Box 50, \\ DK-8830 Tjele, Denmark
}

\section{ABSTRACT}

Housing calves in large groups is associated with a higher risk of respiratory disease and with increased difficulties in identifying diseased animals compared with single housing. The aim of the present study was to investigate the effect of clinical disease on some behaviors recorded by automatic milk feeders in preweaned dairy calves. The experiment included 27 calves from a Danish research farm and 41 calves from a Swedish research farm. The calves were fed restrictively from a computer-controlled milk feeder, and all calves were subjected to daily clinical examinations for 3 to $26 \mathrm{~d}$, with information gathered on general condition, nasal discharge, lung auscultation findings, coughing, signs of dehydration, naval status, rectal temperature, fecal consistency, and presence of chin abscess, arthritis, umbilical hernia, poor body condition, and poor hair coat. Calves suffering from diarrhea, respiratory disease, fever, or unspecific decreased general condition for more than $2 \mathrm{~d}$ were considered to be diseased and were declared to have recovered when they had been free of clinical signs of the disease for at least $2 \mathrm{~d}$. The effects of clinical status (healthy, diseased) on the number of rewarded and unrewarded visits to the calf feeder and drinking rate, respectively, were analyzed by variance component analysis using a mixed model. Milk consumption on diseased and nondiseased days within calves was compared using a Wilcoxon signed rank test. In total, 53 of the calves were diagnosed as diseased during the study period. All cases of diseases were mild and were associated with an unaffected or only mildly affected general condition. Diarrhea was diagnosed in 51 calves, 6 of which also had respiratory disease. In 2 calves, respiratory disease was the only diagnosis. Eleven calves had an unspecific decreased general condition. The number of unrewarded visits was significantly reduced when calves were diseased. In Swedish calves, there was also a tendency for rewarded visits

Received July 3, 2006.

Accepted September 19, 2006.

${ }^{1}$ Corresponding author: catarina.svensson@hmh.slu.se to be reduced during diseased days. Drinking rate and number of rewarded visits increased with increasing age. No effect of clinical status on milk consumption was detected. The number of unrewarded visits was the most sensitive of the 4 feeding behaviors monitored to indicate clinical disease in calves fed restricted milk volumes.

Key words: calf, disease indicator, automatic calf feeder

Group housing of preweaned calves is attracting increasing interest mainly because of concerns for calf welfare and labor efficiency. However, large group sizes are associated with a higher risk of respiratory disease compared with single housing (Maatje et al., 1993; Svensson et al., 2003, 2006) and difficulties in identifying diseased calves. When using manual feeding, minor reductions in calves' appetites can easily be detected and used as an indicator of disease. The development of equally sensitive indicators to help calf caretakers identify diseased calves when housed in groups with automatic milk feeders is welcome. In feedlot calves, radio frequency technology, which records the total time spent at the feed bunk, was found to identify diseased calves $4 \mathrm{~d}$ earlier than experienced stock people (pen riders; Quimby et al., 2001). Feeding behavior (time spent at the feed alley) was also found to be a sensitive indicator of clinical metritis in dairy cows (Urton et al., 2005). Automatic milk feeders may closely monitor the feeding behavior of preweaned calves, and generally alarm lists are based on the milk consumption of the calves. However, milk consumption may not be the most sensitive measure. In some cases, the drinking rate is included as an additional measure, but although Maatje et al. (1993) found that drinking rate was associated with disease in veal calves, the authors concluded that it was an unsatisfactory disease indicator because of the high proportion of false-positive alarms. The aim of the present study was to investigate the effect of clinical disease on milk consumption, drinking rate, and number of rewarded and unrewarded visits to milk feeders in group-housed dairy calves. 
All preweaned calves in group pens with automatic milk feeders were examined on one Swedish $(\mathbf{S} ; \mathrm{n}=41)$ and one Danish $(\mathbf{D} ; \mathrm{n}=27)$ dairy farm. Calves were of different breeds (S: 16 Swedish Holsteins, 25 Swedish Red and Whites; D: 7 Jerseys, 11 Danish Reds, 9 Holstein-Friesians) and of both sexes. Data for days when calves were gradually being weaned was excluded, and only calves that were examined for more than $2 \mathrm{~d}$ within the 3-wk (S) and 9-wk (D) study periods were included. Different types of milk feeders were used on the 2 farms (S: CF300; DeLaval, Tumba, Sweden; and D: HL100; Calvex, Højslev, Denmark). The Danish feeder (see details in Jensen, 2004) subdivided each 24-h period into 2 12-h feeding periods, and within each of these, the calves could have half their daily milk allowance (7.2 $\mathrm{L}$; in Jerseys, $5.6 \mathrm{~L}$ ) in a minimum of 2 portions, but at least $30 \mathrm{~min}$ had to pass between successive milk portions (minimum of $1.8 \mathrm{~L}$; in Jerseys, minimum of $1.4 \mathrm{~L}$ ). Thus, the Danish feeder offered the calves a minimum of 4 portions per day. The Swedish milk feeder allowed a portion (minimum of $0.5 \mathrm{~L}$ ) to be ingested according to a time qualification scheme; at the daily allowance of $8.5 \mathrm{~L}$, a 0.5 -L portion was available approximately $1.5 \mathrm{~h}$ after the previous portion had been ingested. Thus, the Swedish feeder offered the calves a maximum of 17 portions per day. Calves were kept individually from birth and were transferred to group pens at 12 to $14 \mathrm{~d}(\mathrm{~S})$ or $10 \mathrm{~d}(\mathrm{D})$ of age. Group sizes were 5 to 7 (S) or 8 to 10 (D). In addition to milk replacer, the calves were offered hay and calf starter ad libitum.

The milk feeder unit recorded and stored data regarding the calves' use of the milk feeder and milk intake as described by Jensen (2004). The drinking rate was obtained from the standard printout of the Swedish feeder, whereas on the Danish farm it was calculated by dividing the amount of milk ingested by the duration of time with milk in the mixer bowl during visits.

Swedish calves were examined by a veterinarian daily, whereas on the Danish farm a specially trained technician performed the examinations on weekdays only. Calves were considered diseased if they had any of the following conditions for more than $2 \mathrm{~d}$ : arthritis (swelling of one or more joints accompanied by lameness, fever, and a reduced general condition), diarrhea (feces of a gruel-like or watery consistency), "dull calf syndrome" (a reduced general condition without other symptoms, except possibly fever), fever (rectal temperature $>39.5^{\circ} \mathrm{C}$; Rosenberger, 1979), omphalophlebitis (warm swelling or abscess formation associated with the umbilical cord, accompanied by fever and a reduced general condition), and respiratory disease (severely increased respiratory sounds or moderately to severely increased respiratory sounds accompanied by fever and coughing or a greyish to yellowish nasal discharge).
Calves were declared to have recovered (become healthy) when they had had a rectal temperature of $\leq 39.5^{\circ} \mathrm{C}$ and an unaffected general condition for more than $2 \mathrm{~d}$. However, if they had suffered from diarrhea, they also needed to have had feces with porridge-like or firmer consistency for more than $2 \mathrm{~d}$, and if they had suffered from respiratory disease, they also needed to have had normal respiratory sounds for more than $2 \mathrm{~d}$. After a calf was declared diseased, it was considered to be diseased until it was declared to have recovered.

The effects of clinical status on the number of rewarded and unrewarded visits and on drinking rate, respectively, were analyzed by variance component analysis using a mixed model (Littell et al., 1996). Besides the calf's clinical status on a particular day (healthy, diseased), the model included age (in days), sex (35 females; 33 males), farm, and clinical status $\times$ farm as fixed variables. As a random effect, the models included pen within farm (S: 7 pens; D: 3 pens), and the correlations between repeated measures on the same calf were modeled as autoregressive. For the number of unrewarded visits and drinking rate, the clinical status $\times$ farm interaction was not significant and was removed from the final model. Some of the variables were transformed by the square root, or by natural logarithm, to meet the assumption of normal distribution of the data, but for those variables that were transformed before analysis, the least squares means and approximate standard errors were back-transformed and presented on the measured scale. Milk consumption was analyzed as the difference between healthy and diseased days within calf using the Wilcoxon signed rank test.

In total $53(78 \%)$ of the calves were diagnosed as diseased at least once during the study period. Diarrhea occurred most frequently and was diagnosed in 51(75\%) of the calves, out of which 14 had more than one episode of disease and 6 were also diagnosed with respiratory disease. Eleven calves (16\%) had dull calf syndrome, 6 calves had respiratory disease as their only diagnosis, one calf had cheek abscess accompanied by a reduced general condition, and one calf was diagnosed as diseased based on the presence of fever without other disease symptoms. The cases were generally mild and none was accompanied by a moderately or severely reduced general condition.

Number of unrewarded visits was associated $(P<$ 0.01 ) with clinical status, and in the Swedish herd, rewarded visits were associated $(P<0.10)$ with disease (Table 1). Drinking rate $\left(\mathrm{F}_{1.181}=6.19 ; P<0.05\right)$ and number of rewarded visits increased with age $\left(\mathrm{F}_{1.204}=\right.$ 4.44; $P<0.05)$. There were differences $(P<0.001$ to $P$ $<0.10$ ) between farms with regard to the number of 
Table 1. Main effect of clinical status (healthy or diseased) on feeding behavior data retrieved from the milk feeder unit in 68 preweaned dairy calves

\begin{tabular}{|c|c|c|c|c|c|c|}
\hline \multirow[b]{2}{*}{ Item } & \multicolumn{2}{|c|}{ Healthy } & \multicolumn{2}{|c|}{ Diseased } & \multirow[b]{2}{*}{$F$} & \multirow[b]{2}{*}{$P$} \\
\hline & Mean & SEM & Mean & SEM & & \\
\hline Unrewarded visits, frequency, 24-h & 19.80 & 2.14 & 15.84 & 1.99 & $\mathrm{~F}_{1.787}=8.81$ & $<0.01$ \\
\hline Drinking rate, $\mathrm{L} / \mathrm{min}$ & 0.662 & 0.024 & 0.653 & 0.023 & & NS \\
\hline Rewarded visits, frequency, 24-h & 7.12 & 0.41 & 6.88 & 0.42 & & NS \\
\hline Rewarded visits, ${ }^{1}$ frequency, $24-\mathrm{h}$ & & & & & $\mathrm{F}_{1.696}=3.52$ & $<0.10$ \\
\hline Danish farm & 4.25 & 0.67 & 4.40 & 0.71 & & \\
\hline Swedish farm & 9.98 & 0.46 & 9.37 & 0.45 & & \\
\hline
\end{tabular}

${ }^{1}$ Interaction between clinical status and farm.

rewarded and unrewarded visits and drinking rate (Table 2).

Today most automatic milk feeders offer alarm lists based on milk consumption, and some also offer alarm functions based on drinking rate. Drinking rate followed by milk consumption was reported by Maatje et al. (1993) to be the most sensitive disease indicator in veal calves. However, we found none of these parameters significantly associated with disease. Although Maatje et al. (1993) did not state the daily milk allowance in their experiment, they claimed that the generous milk allowances fed to the veal calves in their study caused large variations in milk intake and thus made variation attributable to disease more difficult to detect. In the present study, the calves were given 5.6 to 8.1 $\mathrm{L}$ of milk replacer daily, which is more than the amount received by most dairy calves in Sweden and Denmark, but most likely is less than the volumes offered to veal calves in the Dutch experiment. This may be the reason why milk consumption was not affected by disease in the present experiment. Calves on a low milk allowance have more unrewarded visits, and a high level of unrewarded visits most likely reflects hunger (Jensen, 2006). In the present study, calves were on restricted milk allowances and paid quite a few unrewarded visits to the feeder. Hence, the lower level of unrewarded visits on diseased days may reflect a reduction in appetite. The finding that unrewarded visits were associated with disease in the present study, but not in the study by Maatje et al. (1993), may be explained by the differences in milk allowance in the 2 studies. The different results may also be due to differences in diseases levels; in the present study the calves were examined daily or every weekday by a veterinarian or a trained technician. Very few cases were associated with a reduced general condition, and none of the cases were associated with a moderately to severely affected general condition. In the study by Maatje et al. (1993), examinations were performed twice weekly and disease conditions were reported to be more severe.

The criteria for identifying animals as sick naturally influence the sensitivity of disease indicators. In the present study, a very large proportion $(78 \%)$ of the calves were diagnosed as diseased, with diarrhea accounting for most of the cases. It can be argued that the strict definition of diarrhea used in the present study probably overestimated the incidence of this disease. Nevertheless, significant associations were found between use of the milk feeder and disease.

The differences between the 2 farms regarding rewarded and unrewarded visits may be explained by differences in feeder type and setup, different breeds, and different milk allowances on the 2 farms. The feeder type and setup allowed calves on the Swedish farms to have more rewarded visits. The lower number of unrewarded visits for Swedish calves can be partly explained by the higher number of rewarded visits. However, the higher milk allowance of the Swedish calves may also have reduced the number of unrewarded visits, because a high milk allowance reduces unrewarded visits (Jensen, 2006). Although there was a great farm effect on the number of unrewarded visits, there was no clinical status $\times$ farm interaction for this variable, which suggests that it is a genuine effect of clinical

Table 2. Main effect of farm (Danish or Swedish) on feeding behavior data retrieved from the milk feeder unit in 27 preweaned dairy calves from a Danish herd and 41 calves from a Swedish herd

\begin{tabular}{|c|c|c|c|c|c|c|}
\hline \multirow[b]{2}{*}{ Item } & \multicolumn{2}{|c|}{ Danish } & \multicolumn{2}{|c|}{ Swedish } & \multirow[b]{2}{*}{$F$} & \multirow[b]{2}{*}{$P$} \\
\hline & Mean & SEM & Mean & SEM & & \\
\hline Unrewarded visits, frequency, 24-h & 22.85 & 3.63 & 13.25 & 1.89 & $\mathrm{~F}_{1.5}=6.24$ & $<0.10$ \\
\hline Drinking rate, $\mathrm{L} / \mathrm{min}$ & 0.458 & 0.028 & 0.942 & 0.037 & $\mathrm{~F}_{1.6}=100$ & $<0.001$ \\
\hline Rewarded visits, frequency, 24-h & 4.33 & 0.67 & 9.67 & 0.43 & $\mathrm{~F}_{1.6}=44.3$ & $<0.001$ \\
\hline
\end{tabular}


status. The difference in drinking rate may be due to breed differences, to differences between the 2 milk feeders (e.g., different diameter of tubes, or different types of teats), and possibly to the different ways of calculating this measure.

In conclusion, the present study showed that the number of unrewarded visits to automatic milk feeders was associated with clinical status in preweaned dairy calves and indicates that this parameter may be a more sensitive indicator of disease than drinking rate and milk consumption in dairy calves fed restricted milk volumes.

\section{ACKNOWLEDGMENTS}

Maria Olofsson and John Misa Obidah are acknowledged for their help with the examinations of the calves and Eric Decker for help with data editing. We thank the experimental farms (the Danish Cattle Research Centre at Foulum and Nötcenter Viken, Falköping) for placing their animals and facilities at our disposition, and Christine Maria Røntved for her input on clinical examinations. Søren Højsgaard is acknowledged for statistical support.

\section{REFERENCES}

Jensen, M. B. 2004. Computer-controlled milk feeding of dairy calves: The effects of number of calves per feeder and number of milk portions on use of feeder and social behavior. J. Dairy Sci. $87: 3428-3438$.

Jensen, M. B. 2006. Computer-controlled milk feeding of grouphoused calves: The effect of milk allowance and weaning type. J. Dairy Sci. 89:201-206.

Littell, R. C., G. A. Milliken, W. W. Stroup, and R. D. Wolfinger. 1996. SAS System for Mixed Models. SAS Inst., Inc., Cary, NC.

Maatje, K. J., J. Verhoeff, W. D. J. Kremer, A. L. M. Cruijsen, and T. S. G. A. M. van den Ingh. 1993. Automated feeding of milk replacer and health control of group housed veal calves. Vet. Rec. 133:266-270.

Quimby, W. F., B. F. Sowell, J. G. P. Bowman, M. E. Branine, M. E. Hubbert, and H. W. Sherwood. 2001. Application of feeding behaviour to predict morbidity of newly received calves in a commercial feedlot. Can. J. Anim. Sci. 81:315-320.

Rosenberger, G. 1979. Clinical examination of cattle. Verlaug Paul Parey, Berlin, Germany.

Svensson, C., J. Hultgren, and P. A. Oltenacu. 2006. Morbidity in Swedish dairy calves from 3 to 7 months of age, and risk factors for diarrhea and respiratory disease. Prev. Vet. Med. 74:162-179.

Svensson, C., K. Lundborg, U. Emanuelson, and S.-O. Olsson. 2003. Morbidity in Swedish dairy calves from birth to 90 days of age and individual calf-level risk factors for infectious diseases. Prev. Vet. Med. 58:179-197.

Urton, G., M. A. G. von Keyserlink, and D. M. Weary. 2005. Feeding behaviour identifies dairy cows at risk for metritis. J. Dairy Sci. 88:2843-2849. 